\title{
Effect of the Inorganic Nitrogen Source in the Expression of Nitrite Reductase (NirA) in Thermosynechococcus elongatus BP-1
}

\author{
Maite Buxens, María J. Llama, Juan L. Serra* \\ Enzyme and Cell Technology Group, Department of Biochemistry and Molecular Biology, Faculty of Science and \\ Technology, University of the Basque Country (UPV/EHU), Bilbao, Spain \\ Email: *juanl.serra@ehu.es
}

Received 10 September 2014; revised 25 October 2014; accepted 6 November 2014

Copyright (C) 2014 by authors and Scientific Research Publishing Inc.

This work is licensed under the Creative Commons Attribution International License (CC BY). http://creativecommons.org/licenses/by/4.0/

(c) (i) Open Access

\begin{abstract}
Nitrite reductase (NirA, EC 1.7.7.1) from the thermophilic, unicellular, non- $\mathrm{N}_{2}$-fixing cyanobacterium Thermosynechococcus elongatus BP-1 has been cloned and expressed in Escherichia coli. Analysis by SDS-PAGE of the pure recombinant protein $\left(\mathrm{His}_{6} \mathrm{NirA}\right)$ showed two protein bands, one of $58 \mathrm{kDa}$ (corresponding to the theoretical His ${ }_{6} \mathrm{NirA}$ molecular mass) and another of $44 \mathrm{kDa}$. Western blotting and mass spectrometry analyses confirmed that the $44 \mathrm{kDa}$ protein resulted from proteolysis of the intact $\mathrm{His}_{6} \mathrm{NirA}$, and suggested the existence, at the $\mathrm{C}$-terminal domain of the $58 \mathrm{kDa}$ form, of a region particularly sensible to proteolysis or accessible to proteases. A sample of both forms of $\mathrm{His}_{6} \mathrm{NirA}$ was used to obtain anti-NirA polyclonal antibodies. These antibodies were used to assess, by SDS-PAGE followed by Western blotting, the in vivo expression of NirA in wild-type cells of $T$. elongatus BP-1 growing in cultures with nitrate, nitrite or ammonium which were inoculated with cells grown with different nitrogen sources. These analyses revealed that protein bands corresponding to the complete $(58 \mathrm{kDa})$ and truncated $(44 \mathrm{kDa})$ forms of NirA can also be detected in solubilized cells. Moreover, the presence of each of these forms depended on the nitrogen source used to grow cells. Thus, expression of the complete NirA generally predominates in cells growing in medium with nitrate or nitrite. However, the truncated form prevails in cells grown in nitrate or nitrite and then transferred to medium with ammonium. The fact that the patterns of in vivo expression of NirA are different depending on the nitrogen source used possibly relies on a post-translational regulatory mechanism by proteolysis.
\end{abstract}

\section{Keywords}

Cyanobacteria, NirA, Nitrite Reductase Expression, Post-Translational Regulation, Protein Hydrolysis, Thermosynechococcus elongatus BP-1

${ }^{*}$ Corresponding author.

How to cite this paper: Buxens, M., Llama, M.J. and Serra, J.L. (2014) Effect of the Inorganic Nitrogen Source in the Expression of Nitrite Reductase (NirA) in Thermosynechococcus elongatus BP-1. Advances in Microbiology, 4, 1044-1056. 


\section{Introduction}

Although diazotrophic cyanobacteria can assimilate atmospheric $\mathrm{N}_{2}$, the majority of strains use dissolved inorganic salts (ammonium, nitrite or nitrate) or combined nitrogen sources [1]. With a few exceptions, all known cyanobacteria can use both nitrate and nitrite as the sole nitrogen source. For their assimilation these ions must be taken up from the external medium through specific transporters [2] [3]. The multisubunit ATP Binding Cassette $(A B C)$ permease, which can transport either nitrate or nitrite, is present in most cyanobacteria (see [4] for a review). This active uptake transporter is encoded by four genes ( $n r t A, n r t B, n r t C$ and $n r t D)$ integrated in the so-called nitrate assimilation operon (nir $A$ operon), which is flanked by the genes encoding enzymes responsible for the sequential reduction of nitrate to ammonium, i.e., narB (nitrate reductase) and nir $A$ (nitrite reductase). This genic organization (5'-nirA-nrtABCD-narB-3') is conserved among cyanobacteria and guarantees a balanced expression of the proteins responsible for both the uptake and the assimilatory reduction of nitrate [5]. Despite the fact that many cyanobacterial genomes show this nir $A$ operon structure, other gene arrangements have also been reported. However, in all cases, the nirA gene is invariably the first gene of a transcription unit (see [4] for a review).

NirA (ferredoxin:nitrite oxidoreductase, EC 1.7.7.1), the product of nirA, catalyzes the reduction of nitrite (oxidation state +3 ) to ammonium (oxidation state -3 ) using reduced ferredoxin as the electron donor. This enzyme, together with sulphite reductase ( $\mathrm{SiR}$, which reduces sulphite to sulphide), constitutes the only known case of enzymes capable to catalyze six-electron transfer in a single step. This unique property is possible due to the presence of one [4Fe-4S] cluster and one siroheme (which serves as the binding site for nitrite) as prosthetic groups [6] [7]. Characterized NirA of almost all photosynthetic organisms are monomeric enzymes with a molecular mass between $52 \mathrm{kDa}$ and $75 \mathrm{kDa}$ [2] [8]-[12].

In cyanobacteria, nitrate assimilation is also regulated at the post-translational level. Thus, nitrate uptake is inhibited upon the addition of ammonium to the medium and is resumed upon its complete consumption [13][15]. Although the nitrate/nitrite uptake systems, as well as the enzymes involved in their subsequent reduction to ammonium and assimilation, have been studied in detail, little is still known about the regulatory mechanism involved. These studies indicated differences in the regulation of this very complex process among cyanobacteria, making difficult to establish a unique model of regulation. Several issues of short-term regulation exerted by ammonium on nitrate/nitrite uptake and activity of the enzymes involved in its reduction still remain unclear.

The effect of the nitrogen source used to grow cells on NirA activity has been studied in Anacystis nidulans (reclassified Synechococcus leopoliensis) strain L-1402-1 [16] and Phormidium laminosum strain OH-1-p.Cl ${ }_{1}$ (renamed as Geitlerinema sp., PCC 8501) [14] [17]. These authors demonstrated that in both cyanobacteria de novo synthesis of NirA occurred in the absence of an added nitrogen source. Ammonium acted as a repressor of NirA overriding any positive effect of nitrate or nitrite, indicating that the enzyme was ammonium-repressible rather than nitrate- or nitrite-inducible [14]. This conclusion was supported by the fact that nitrogen-starved cells of $P$. laminosum showed higher levels of NirA than their nitrogen-sufficient counterparts [11]. Moreover, in $P$. laminosum the in vivo effect of ammonium on NirA was similar to that exerted by chloramphenicol, suggesting that de novo synthesis of protein was probably repressed by this ion [14].

The intracellular ratio of 2-oxoglutarate to glutamine has been also analyzed in $P$. laminosum under distinct nutritional conditions, leading to different activity levels of nitrate-assimilating enzymes [17]. Transcription of nirA operon genes is strictly regulated by 2-oxoglutarate. This oxoacid is the major intracellular signal for regulation and its concentration varies according to the change in cellular $\mathrm{C} / \mathrm{N}$ balance [14] [17]. Apart from 2oxoglutarate, several regulatory proteins (including NtcA, NtcB, $\mathrm{P}_{\mathrm{II}}$, PipX and CnaT, among others) have been identified and proposed as long-term regulators of nitrate assimilation in cyanobacteria (see [2] [4] for reviews). Recently, Puerta-Fernández and Vioque [18] reported that the RNA chaperone Hfq is also involved in the regulation of the nirA operon in Anabaena sp. PCC 7120, although the mechanism for this regulation is still unknown. Frías and Flores [19] also proposed NirA as a key element in the negative regulation of the nirA operon in the absence of ammonium in Anabaena sp. PCC 7120. These authors suggest that NirA is a trigger enzyme that, in addition to its role in nitrite reduction to ammonium, exerts a negative regulatory role though a mechanism to be elucidated.

The genome sequence of thermophilic, unicellular, non- $\mathrm{N}_{2}$-fixing cyanobacterium Thermosynechococcus elongatus BP-1 [20] revealed the presence of the nirA operon [4] [21], which confers to this cyanobacterium the capacity to grow with nitrate or nitrite as unique nitrogen sources. In the present study, the nirA gene of T. elon- 
gatus BP-1 has been cloned and overexpressed in Escherichia coli. The recombinant $\mathrm{His}_{6} \mathrm{NirA}$ protein has been purified and used as antigen to obtain polyclonal antibodies. These antibodies have been successfully used to assess the in vivo expression of NirA in wild-type cells of $T$. elongatus BP-1 growing in cultures with different nitrogen sources.

\section{Materials and Methods}

\subsection{Materials}

Oligonucleotides were obtained from Bonsaitech (Madrid, Spain) and Taq polymerase from 5PRIME (Gaithersburg, MD, USA). Escherichia coli cells (M15 strain), plasmids, and plasmidic DNA purification systems were obtained from Qiagen (Hilden, Germany). Genomic DNA purification system was purchased from Macherey Nagel (Düren, Germany), $\mathrm{Ni}^{2+}$-Chelating Sepharose ${ }^{\mathrm{TM}}$ Fast-Flow, and isopropyl-thio- $\beta$-D-galacto-pyranoside (IPTG) were obtained from GE Healthcare (Uppsala, Sweden). Anti-His tag antibody and anti-rabbit and anti-mouse IgG were purchased from Sigma-Aldrich (St. Louis, MO, USA). All other chemicals were of analytical or molecular biology grade.

\subsection{Organism and Cell Culture}

The thermophilic, unicellular, non-diazotrophic cyanobacterium Thermosynechococcus elongatus BP-1 (NIES2133) was originally obtained from Prof. M. Rögner (University of Bochum, Germany). Cells were grown photoautotrophically at $48^{\circ} \mathrm{C}$ in $250 \mathrm{ml}$ Erlenmeyer flasks containing $100 \mathrm{ml}$ of sterile BG11 [22] mineral medium. Flasks were shaken at 140 - $180 \mathrm{rpm}$ and continuously illuminated by fluorescent lamps providing a light intensity of about $20-50 \mu \mathrm{E} \cdot \mathrm{m}^{2} \cdot \mathrm{s}^{-1}$. Air atmosphere inside the orbital incubator (Kuhner Shaker X, Basel, Switzerland) was enriched with $1 \%(\mathrm{v} / \mathrm{v}) \mathrm{CO}_{2}$.

Sterile culture medium was used either without nitrogen source added (medium BG11 $1_{0}$ ) or supplemented in each case with the indicated inorganic nitrogen salt. Nitrate or nitrite was added as sodium salt and sterilized in autoclave. Ammonium was supplemented as sulphate, using a $100 \mathrm{mM}$ stock solution sterilized by filtration $(0.2$ $\mu \mathrm{m}$ Millex ${ }^{\circledR}$-FG filter, Millipore Co., Bedford, MA, USA) before addition to sterile BG $11_{0}$ medium. The final concentration of nitrogen in the culture media was $4 \mathrm{mM}$ in all cases.

\subsection{Analytical Methods}

Protein concentration was determined by the Bradford [23] method using crystalline bovine serum albumin (Sigma-Aldrich) as standard T. elongatus BP-1 growth was assessed by measuring the turbidity of cultures at $730 \mathrm{~nm}$ in a DU ${ }^{\mathbb{R}} 800 \mathrm{UV} /$ Vis spectrophotometer (Beckman Coulter Inc., Fullerton, CA, USA).

\subsection{Cloning and Purification of NirA from T, elongatus BP-1}

T. elongatus BP-1 genomic DNA was extracted and purified using Nucleo Spin Tissue Kit (Machery Nagel). PCR was performed using the oligonucleotides 5'-GTGAGCAACAAAATTGAAGC-3' and

5'-TTAGGAGACCATCATGGCCA-3', designed using the T. elongatus BP-1 nirA sequence obtained from genome.kazusa.or.jp/cyanobase. A DNA fragment of 1536 bp carrying the NirA coding region was amplified. DNA was purified from the agarose band using the DNA Gel Extraction Kit (Millipore Co.) and cloned into the vector pQE-30UA using a Ligation Mixture Mix (Qiagen). The resulting plasmid (pQE-30UA-nirA) carried a chimeric gene, which encoded a fusion protein consisting of an N-terminal amino acid tag with six consecutive histidine residues. The final expression plasmid was verified by DNA sequencing Cells of $E$. coli strain M15 [pREP4] were transformed with the expression plasmid and grown overnight at $37^{\circ} \mathrm{C}$ in Luria-Bertani medium $(2 \times 100 \mathrm{ml})$ supplemented with ampicillin $\left(100 \mathrm{mg} \cdot \mathrm{l}^{-1}\right)$ and kanamycin $\left(25 \mathrm{mg} \cdot \mathrm{l}^{-1}\right)$. Then, this culture was used to inoculate 11 of medium containing per liter: $10 \mathrm{~g}$ tryptone, $5 \mathrm{~g}$ yeast extract, $10 \mathrm{~g} \mathrm{NaCl}, 100 \mathrm{mg}$ ampicillin and $25 \mathrm{mg}$ kanamycin. Cells were grown at $37^{\circ} \mathrm{C}$ under vigorous orbital shaking. When the $A_{600}$ of cultures reached a value of $0.8,0.3 \mathrm{mM}$ IPTG was added, and temperature lowered to $25^{\circ} \mathrm{C}$. After $90 \mathrm{~min}$ of induction, cells were collected by centrifugation $\left(10 \mathrm{~min}\right.$, at $\left.8000 \times \mathrm{g}, 4^{\circ} \mathrm{C}\right)$ and stored at $-20^{\circ} \mathrm{C}$ until needed. To isolate $\mathrm{His}_{6} \mathrm{NirA}$, the pelleted biomass from a 11 of culture was suspended in $25 \mathrm{ml}$ of lysis Buffer A ( $50 \mathrm{mM}$ Tris- $\mathrm{HCl}$, $300 \mathrm{mM} \mathrm{NaCl}, 10 \mathrm{mM}$ imidazole, $\mathrm{pH}$ 7.3). The cell suspension was incubated for $1 \mathrm{~h}$ at $4^{\circ} \mathrm{C}$ with $0.1 \%(\mathrm{w} / \mathrm{v})$ 
lysozyme, and finally disrupted for 15 min by sonication (Branson Sonifier ${ }^{\circledR} 250$, Danbury, CT, USA) at $14 \%$ amplitude ( $60 \mathrm{~s}$ on/30 s off).

The cell lysate was centrifuged $\left(30 \mathrm{~min}\right.$, at $\left.9500 \times \mathrm{g}, 4^{\circ} \mathrm{C}\right)$ and the clear supernatant was loaded onto a $\mathrm{Ni}^{2+}-$ Chelating Sepharose Fast-Flow column equilibrated in buffer A. The column $(1.5 \mathrm{~cm} \times 4 \mathrm{~cm})$ was washed with 30 column volumes of $50 \mathrm{mM}$ Tris- $\mathrm{HCl}, 300 \mathrm{mM} \mathrm{NaCl}, 20 \mathrm{mM}$ imidazole, $\mathrm{pH}$ 7.3. Then, $\mathrm{His}_{6} \mathrm{NirA}$ was eluted with a linear gradient of imidazole (from $20 \mathrm{mM}$ to $250 \mathrm{mM}$ ) in $50 \mathrm{mM}$ Tris- $\mathrm{HCl}, 300 \mathrm{mM} \mathrm{NaCl}$, and pH 7.3 . The same buffer containing $250 \mathrm{mM}$ imidazole was supplied until the complete elution of enzyme. A flow-rate of $1 \mathrm{ml} \mathrm{min}{ }^{-1}$ was used in all steps. The elution was monitored continuously at $280 \mathrm{~nm}$, and $1.5-\mathrm{ml}$ fractions were collected and analyzed by SDS-PAGE followed by Western blotting.

\subsection{Electrophoretical Analysis and Immunodetection}

SDS-PAGE was performed in a homogeneous $12 \%$ (w/v) acrylamide running gel and an upper $4 \%(\mathrm{w} / \mathrm{v})$ acrylamide stacking gel. Gels were run in a Mini Protean III apparatus (Bio-Rad, Hercules, CA, USA). When proteins were not transferred for immunodetection, bands were visualized after staining with Coomassie brilliant blue R-250. In order to estimate protein molecular sizes, Unstained Precision Plus Protein Standards (Bio-Rad, denoted as M1 in Figure 1(a)) were used. When proteins separated in gels were transferred to nitrocellulose membranes, Prestained SDS-PAGE Standards Broad Range (Bio-Rad, denoted as M2 in Figure 1(b)) markers were used. In this case, prior to transference, membranes and gels were pre-equilibrated for $20 \mathrm{~min}$ in transference buffer $(0.30 \% \mathrm{w} / \mathrm{v}$ Tris, $1.44 \% \mathrm{w} / \mathrm{v}$ glycine in $20 \% \mathrm{v} / \mathrm{v}$ methanol).

Western blotting analysis was performed after transferring proteins from gels to nitrocellulose membranes for $1 \mathrm{~h}$ at $150 \mathrm{~mA}$. The membranes were then incubated for $16 \mathrm{~h}$ at $4^{\circ} \mathrm{C}$ in blocking buffer containing Tris-buffered saline (TBS, $50 \mathrm{mM}$ Tris, $150 \mathrm{mM} \mathrm{NaCl}, \mathrm{pH} 7.5)$ supplemented with $1 \%(\mathrm{w} / \mathrm{v})$ bovine serum albumin and $0.3 \%$ $(\mathrm{v} / \mathrm{v})$ tween 20. Therefore, corresponding antibodies ( anti-His $_{6}$ tag or anti-His $\left.{ }_{6} \mathrm{NirA}\right)$ were added and membranes were incubated for $1 \mathrm{~h}$ with gentle shaking. After several washes with TBS, membranes were incubated for $1 \mathrm{~h}$ with anti-rabbit or anti-mouse IgG (depending on the assay) conjugated to alkaline phosphatase. Once washed with TBS, membranes were developed using nitro-blue tetrazolium chloride and 5-bromo-4-chloro-3'-indolyphosphate $p$-toluidine salt (NBT-BCIP ${ }^{\circledR}$ ) (Sigma-Aldrich).

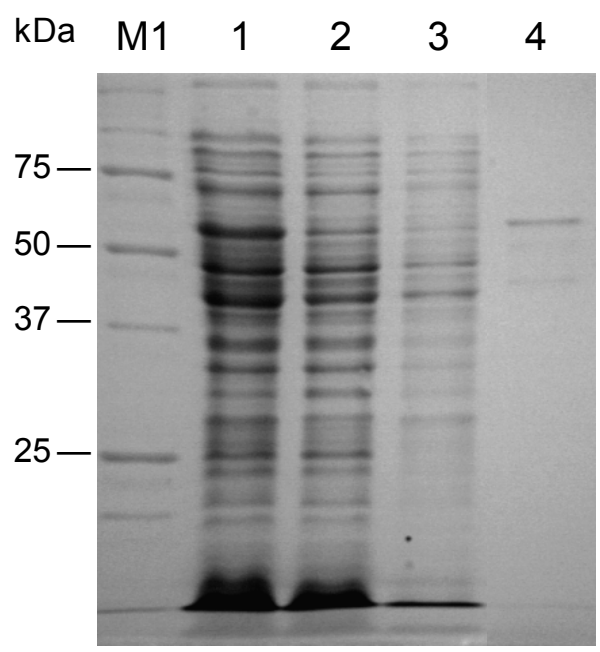

(a)

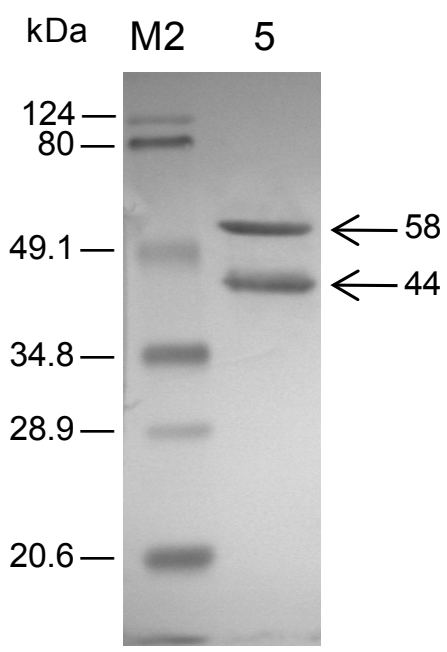

(b)

Figure 1. Assessment of the expression and purification of $\mathrm{His}_{6} \mathrm{NirA}$ analyzed in two different homogenous polyacrylamide gels: (a) SDS-PAGE, stained with Coomassie brilliant blue; (b) Western blot, revealed with anti-His 6 tag antibody. Lanes M1 and M2, molecular mass markers (see Materials and Methods); Lane 1, supernatant of the cell lysate; Lane 2, flow-through from the IMAC column; Lane 3, eluate of IMAC column with $20 \mathrm{mM}$ imidazole; Lane 4, a sample of the pooled most active fractions of $\mathrm{His}_{6} \mathrm{NirA}$ eluted with $250 \mathrm{mM}$ imidazole; Lane 5, Western blot of the sample analyzed in Lane 4. 


\subsection{In-Gel Tryptic Digestion of Proteins, Liquid Chromatography and Mass Spectrometry}

Protein bands of interest were cut from polyacrylamide gels and subjected to tryptic digestion. Once dehydrated with acetonitrile the withdrawn proteins were in situ digested with trypsin $\left(12.5 \mathrm{ng} \cdot \mu \mathrm{l}^{-1}\right)$ for $16 \mathrm{~h}$ at $37^{\circ} \mathrm{C}$. In tandem mass spectrum were obtained using a SYNAPT HDMS mass spectrometer (Waters Corporation, Milford, MA, USA) connected to a NanoAcquity UPLC (Waters) chromatography system. A sample $(8 \mu \mathrm{l})$ obtained after tryptic digestion was loaded onto a Symmetry $300 \mathrm{C} 18,180 \mu \mathrm{m} \times 20 \mathrm{~mm}$ (Waters) column. The column was washed with $0.1 \%(\mathrm{v} / \mathrm{v})$ formaldehyde for $3 \mathrm{~min}$ using a $5 \mu \mathrm{l} \cdot \mathrm{min}^{-1}$ flow-rate, and connected to a $75 \mu \mathrm{m} \times 200$ $\mathrm{mm}, 1.7 \mu \mathrm{m}$ BEH130 C18 column (Waters) equilibrated with 3\% (v/v) acetonitrile containing $0.1 \%(\mathrm{v} / \mathrm{v})$ formic acid. The flow-rate was adjusted to $0.3 \mu \mathrm{l} \cdot \mathrm{min}^{-1}$ and peptides were eluted with a linear gradient (30 min) of acetonitrile from $3 \%$ to $60 \%(\mathrm{v} / \mathrm{v})$. Voltage was adjusted from 3000 to $3500 \mathrm{~V}$.

Mass spectrometric (MS/MS) analysis was performed with the mass spectrometer programmed in mode DDA (Data Dependent Acquisition) in order to fragment the three most intense precursors of each scan within an interval $\mathrm{m} / \mathrm{z}$ ranging from 350 to 1990 , presenting 2, 3 or 4 positive charges and intensities starting from 20 counts/scan. Mass spectra were processed with VEMS program [24] and analyzed using the NCBI database and the on-line form of the MASCOT program (http://www.matrixscience.com).

\subsection{Antibodies}

Samples of $\mathrm{His}_{6} \mathrm{NirA}$ purified by IMAC, containing both the complete $(58 \mathrm{kDa})$ and truncated $(44 \mathrm{kDa})$ forms of the recombinant protein, were provided to Abyntek Biopharma, S.L. to immunize a set of rabbits according to standard protocols in order to obtain polyclonal antibodies raised against $\mathrm{His}_{6} \mathrm{NirA}$.

\subsection{In Vivo Expression of NirA in Wild-Type Cells of T. elongatus BP-1}

Prior to the expression studies, cells of $T$. elongatus BP-1 were acclimated to grow with different nitrogen sources through several subcultures in media containing nitrate, nitrite or ammonium as the sole nitrogen source. When cells were acclimated to the corresponding nitrogen source, they were grown in their respective medium until the cultures reached the exponential phase of growth. In this moment, cells were harvested and washed (three times with BG11 $1_{0}$ medium) by centrifugation at room temperature for $5 \mathrm{~min}$, at $1500 \times \mathrm{g}$ (Allegra ${ }^{\mathrm{TM}} \mathrm{X}-22 \mathrm{R}$ centrifuge, Beckman Coulter Inc.). Finally, aliquots of each type of cells were used to inoculate flaks containing $100 \mathrm{ml}$ of medium BG11, either without nitrogen source or supplemented with nitrate, nitrite or ammonium at a final nitrogen concentration of $4 \mathrm{mM}$. Then, inoculated flasks were incubated in the orbital shaker under the same conditions used to grow cells. Duplicate samples $(1 \mathrm{ml})$ of each culture were withdrawn at $0,1,3,6,9,24$, 48 and $96 \mathrm{~h}$ and deposited in $1.5 \mathrm{ml}$ Eppendorf tubes. One of the collected samples was used to estimate cell density. The biomass from the other one was harvested by centrifugation at room temperature for 5 min at 2000 $\times$ g (Microfuge ${ }^{\circledR}$ 18, Beckman Coulter Inc.). The liquid supernatant was discarded and the pelleted cells were immediately frozen and stored at $-80^{\circ} \mathrm{C}$. Once all samples were collected, SDS-PAGE loading buffer was added to each tube (proportionally to cell density previously determined) in order to disrupt cells and completely solubilized proteins. Samples were incubated for $5 \mathrm{~min}$ at $95^{\circ} \mathrm{C}$, centrifuged for $10 \mathrm{~min}$ at $12,000 \times \mathrm{g}$, and, finally $10 \mu 1$ of each supernatant was analysed by SDS-PAGE. After electrophoretical separation, protein detection was carried out by Western blotting using anti-His ${ }_{6} \mathrm{NirA}$ (diluted 1/1000 v/v in TBS) as a primary antibody. The expression results shown in this study have been obtained in triplicate cultures and duplicate Western blotting analyses with consistent results, although only one Western blot membrane is shown. To quantify the proteins revealed in the Western blot membranes, digital images were taken using a Pentax *istD camera. Then, images were analyzed using the TLC Analyzer software [25] available free at

http://www.sciencebuddies.org/science-research-papers/tlc analyzer.shtml, and results were exported and integrated numerically in a spreadsheet.

\section{Results}

\subsection{Cloning and Purification of $\mathrm{His}_{6} \mathrm{NirA}$}

In this work nitrite reductase from T. elongatus BP-1 has been successfully cloned and expressed as a hexahistidine-tagged protein in host cells of E. coli M15, as detailed in the Materials and Methods section. The recombinant protein was purified by a procedure which is fast, easy to accomplish and yields about $6 \mathrm{mg}$ of a pure prep- 
aration of soluble $\mathrm{His}_{6} \mathrm{NirA}$ per liter of culture. The protein was strongly retained by the IMAC resin and eluted at the end of the imidazole gradient (about $250 \mathrm{mM}$ imidazole). Analysis of fractions by SDS-PAGE followed

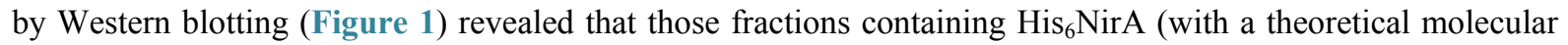
mass of $58,487 \mathrm{kDa}$ ), contained another protein of about $44 \mathrm{kDa}$. Moreover, all fractions containing the $58 \mathrm{kDa}$ recombinant protein showed NirA activity (measured with reduced dithionite-methyl viologen as reported by Arizmendi and Serra [11], indicating that the $\mathrm{His}_{6} \mathrm{NirA}$ expressed in E. coli cells is active (data not shown). Both the 58- and 44-kDa proteins were maintained soluble in diluted preparations stored at $4^{\circ} \mathrm{C}$ for at least 7 days without apparent loss of their NirA activity. However, they showed a strong tendency to form aggregates and precipitate at concentrations above $1 \mathrm{mg} \cdot \mathrm{ml}^{-1}$. Thus, $2 \mathrm{mM}$ nitrite was added to the samples in order to enhance the stability of the soluble proteins.

\subsection{Analysis of Purified Proteins by Western Blotting and Mass Spectrometry}

In order to ascertain that the $44 \mathrm{kDa}$-protein was not the result of intact $\mathrm{His}_{6} \mathrm{NirA}$ proteolysis occurring during the purification procedure, all purification steps were carried out at $4{ }^{\circ} \mathrm{C}$ and a protease inhibitor cocktail was added. Even under these conditions, the $44 \mathrm{kDa}$-protein always coeluted with the complete $58 \mathrm{kDa}$ form (results not shown). Western blotting analysis of samples of E. coli cells during the induction of protein expression by IPTG confirmed that the $44 \mathrm{kDa}$-protein also carries the extension of hexahistidine residues, and that can be overexpressed in E. coli cells after the addition of IPTG (Figure 2). Mass spectrometry analyses of the protein bands sliced out from the SDS-polyacrylamide gel corresponding to the $44 \mathrm{kDa}$ and $58 \mathrm{kDa}$ forms of $\mathrm{His}_{6} \mathrm{NirA}^{\mathrm{N}}$ (Figure 3) are in agreement with former results, indicating that the $44 \mathrm{kDa}$-protein is a truncated form of the 58 $\mathrm{kDa} \mathrm{His}{ }_{6} \mathrm{NirA}$ lacking a polypeptide located at the carboxyl domain.

\subsection{Anti-His 6 NirA Antibodies Evaluation}

The specificity of the obtained rabbit polyclonal antibodies (rose against the purified complete and truncated forms of $\mathrm{His}_{6} \mathrm{NirA}$ ) to recognize NirA in extracts of wild-type cells of $T$. elongatus BP-1 was evaluated. Several dilutions $\left(1: 10\right.$ and $1: 20 \mathrm{v} / \mathrm{v}$ ) of cell extracts (initially containing $100 \mu \mathrm{g}$ protein $\mathrm{ml}^{-1}$ ) were analyzed by SDSPAGE followed by Western blotting using different antibodies dilutions (1/500, 1/1000 and 1/2000 v/v). Western blotting analysis revealed the presence of two bands of NirA whose molecular masses matched well with those previously calculated for the complete $(58,487 \mathrm{kDa})$ and truncated (approx. $44 \mathrm{kDa}$ ) forms of the recombinant $\mathrm{His}_{6} \mathrm{NirA}$.

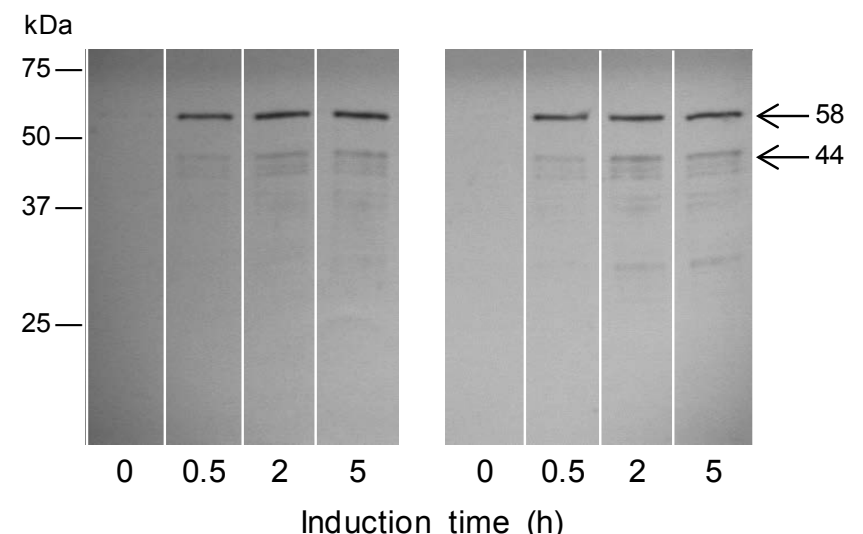

(a)

(b)

Figure 2. Induction by IPTG of the expression of $\mathrm{His}_{6}-\mathrm{NirA}$ in $E$. coli cells transformed with pQE-30UA-nirA. The protein was induced by the addition of $0.3 \mathrm{mM}$ IPTG and incubating the cultures at (a) $25^{\circ} \mathrm{C}$ or (b) $30^{\circ} \mathrm{C}$. Analysis by SDS-PAGE followed by Western blotting was done in samples of cells withdrawn before induction (time 0 ) and at the indicated times after the addition of IPTG. Culture samples were centrifuged and the pelleted cells were completely solubilized with loading buffer. Monoclonal anti-His ${ }_{6}$ tag antibody, diluted at $1 / 10,000(\mathrm{v} / \mathrm{v})$, was used as primary antibody. 


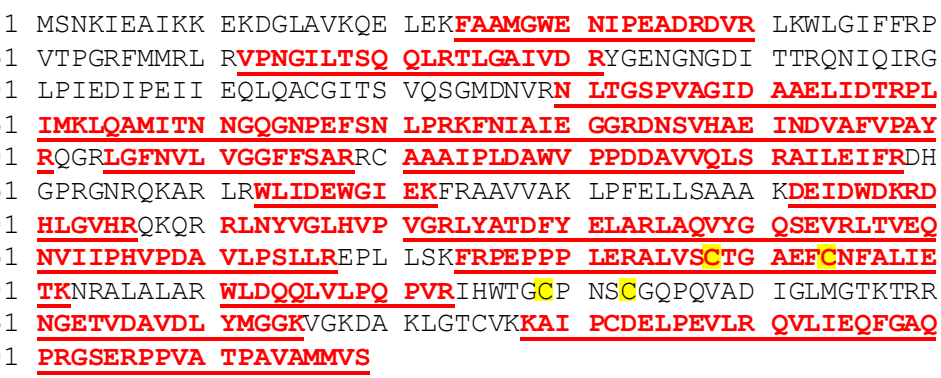

(a)

1 MSNKIEAIKK EKDGLAVKQE LEKFAAMGWE NIPEADRDVR LKWLGIFFRP

51 VTPGRFMMRL RVPNGILTSQ QLRTLGAIVD RYGENGNGDI TTRQNIQIRG

101 LPIEDIPEII EQLQACGITS VQSGMDNVRN LTGSPVAGID AAELIDTRPI

151 IMKLQAMITN NGQGNPEFSN LPRKFNIAIE GGRDNSVHAE INDVAFVPAY

201 RQGRLGFNVL VGGFFSARRC AAAIPLDAWV PPDDAVVQLS RAILEIFRDH

251 GPRGNRQKAR LRWLIDEWGI EKFRAAVVAK LPFELLSAAA KDEIDWDKRD

301 HLGVHRQKQR RLNYYGLHVP VGRLYATDFY ELARLAQVYG QSEVRLTVEO

351 NVIIPHVPDA VLPSLLREPL LSKFRPEPPP LERALVSCTG AEFCNFALIE

401 TKNRALALAR WLDQQLVLPQ PVRIHWTGCP NSCGQPQVAD IGLMGTKTRR

451 NGETVDAVDL YMGGKVGKDA KLGTCVKKAI PCDELPEVLR QVLIEQFGAQ

501 PRGSERPPVA TPAVAMMVS

(b)

Figure 3. Analysis by in-gel tryptic digestion followed by mass spectrometry of (a) $58 \mathrm{kDa}$ and (b) $44 \mathrm{kDa}$ forms of $\mathrm{His}_{6} \mathrm{NirA}$ previously separated by SDS-PAGE. The identified peptides corresponding to NirA sequence appear in red colour and underlined. The four Cys residues (in positions 388, 394, 429 and 433) involved in the anchoring to the protein of the siroheme and iron-sulphur cluster appear shadowed in yellow color. The C-terminal polypeptide sequence (amino acids 384 - 519) not identified in the truncated form of $\mathrm{His}_{6} \mathrm{NirA}$ appeared marked in italics typeface and in blue colour.

\subsection{Effect on the Expression in Vivo of NirA of the Nitrogen Source Used to Grow T. elongatus BP-1}

Anti-His ${ }_{6} \mathrm{NirA}$ antibody was used to assess the expression of NirA in wild-type cells of T. elongatus BP-1 growing in media containing different inorganic nitrogen sources. Due to the fact that these polyclonal antibodies recognize both the complete and the truncated form of NirA, the expression of both proteins was monitored simultaneously with the aim of detecting variations due to the nitrogen source used and/or the time-course of their expression in cells. For this purpose, cells were initially grown in BG11 $1_{0}$ medium supplemented with ammonium, nitrite or nitrate as the sole nitrogen source. At the exponential phase of growth, cells of each culture were subsequently used to inoculate (using similar initial cell density, $A_{730}=0.14 \pm 0.04$, in all cases), fresh BG11 $1_{0}$ medium supplemented with ammonium, nitrite, nitrate or without nitrogen source ( $\mathrm{N}$-free medium). In all cases, growth was followed by determining, at the indicated times, cell density of cultures growing in the four different nitrogen sources indicated above (Figure 4, upper panels) and which were inoculated with cells grown in ammonium (Figure 4(a)), nitrite (Figure 4(b)) or nitrate (Figure 4(c)), respectively. Simultaneously, the time-course appearance of NirA forms was analyzed in the twelve cultures by Western blotting from cell samples withdrawn in the initial $96 \mathrm{~h}$ of culture (Figure 4, lower panels).

To investigate NirA expression, cells acclimated to grow with a specific nitrogen source were transferred to media containing another nitrogen source or to a N-free medium. In all cases, cells grew better in media containing ammonium or nitrate than nitrite as the sole nitrogen source (Figure 4, upper panels), no matter which nitrogen source was used to grow cells used as inocula. At the initial stages, growth with nitrite is even slower than that observed in a $\mathrm{N}$-free medium. These results demonstrate once more that nitrite concentration is critical for cyanobacterial growth and that this anion can be toxic if it is accumulated inside cells [14] [26].

The expression profiles of NirA depended on the inorganic nitrogen source used to grow cells. Thus, both the complete $(58 \mathrm{kDa})$ and truncated $(44 \mathrm{kDa})$ forms of NirA are present in some cases, whereas only one of them can be clearly detected in other situations. Furthermore, expression profiles change not only depending on the 

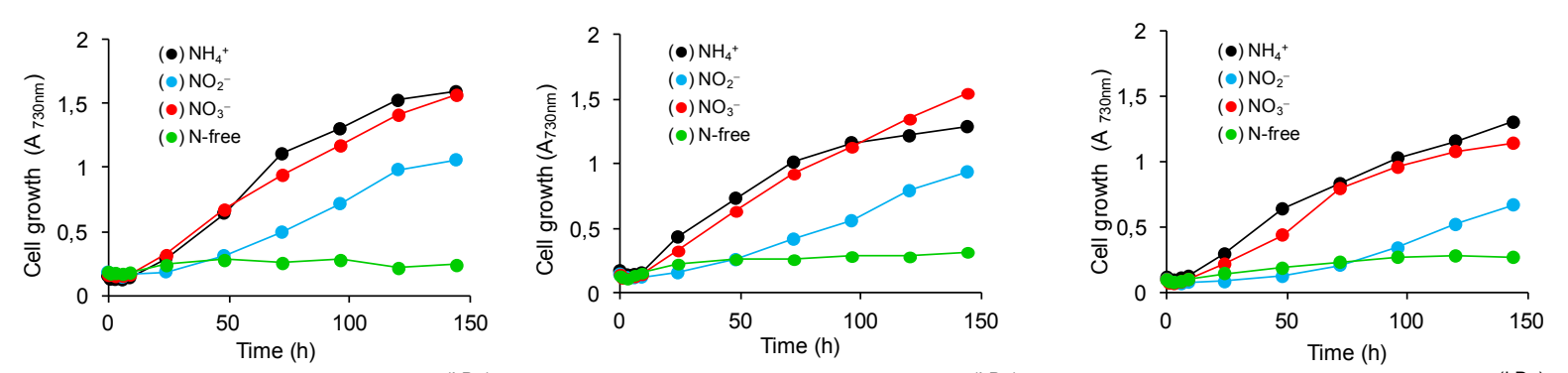

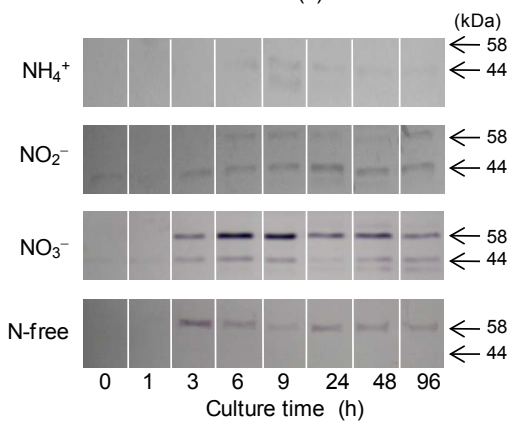

(a)

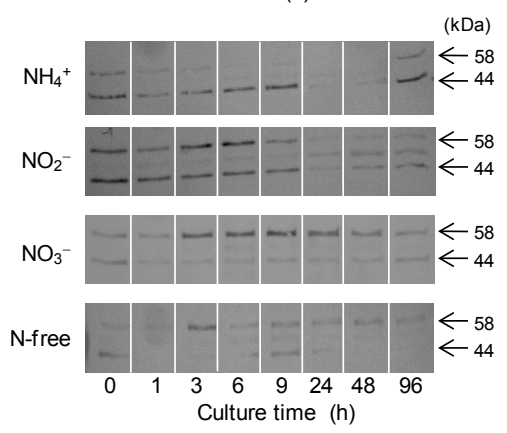

(b)

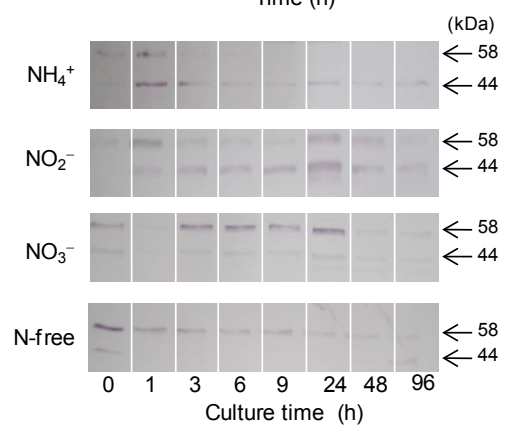

(c)

Figure 4. Assessments of growth (upper panels) and time-course expression (lower panels) of NirA in cultures of $T$. elongatus BP-1 with different nitrogen source. Flasks containing BG1 $1_{0}$ medium were supplemented with ammonium, nitrite or nitrate (as the sole nitrogen source) or without added nitrogen ( $\mathrm{N}$-free). Then flasks were inoculated with cultures of cells grown in ammonium (a) $\mathrm{HH}_{4}{ }^{+}$, nitrite (b) $\mathrm{NO}_{2}{ }^{-}$or nitrate (c) $\mathrm{NO}_{3}{ }^{-}$. Cell growth was determined by turbidity measurements. The expression of NirA was assessed by Western blotting using samples of cultures withdrawn at the indicated times of culture. The arrows indicate the positions of the complete and truncated forms of NirA.

nitrogen source present in the media, but also with the age of culture (Figure 4, lower panels).

Thus, when cultures were growing with ammonium, independently whether cells used as inocula were grown with ammonium, nitrite or nitrate, the truncated NirA is the major form detected in most cases. Complete NirA can also be detected, particularly when cells used as inocula were grown with ammonium, nitrite or nitrate, the truncated NirA is the major form detected in most cases. Complete NirA can also be detected, particularly when cells used as inocula were grown with nitrate. These results indicate that, in the case of T. elongatus BP-1, even when ammonium is the sole nitrogen source available, a negligible amount of NirA could be observed, although the protein is detected mainly as an inactive truncated $44 \mathrm{kDa}$ protein. When cultures were growing with nitrite, both complete and truncated forms of NirA were detected no matter the nitrogen source used to grow inocula.

When cultures were growing with nitrate, independently whether the cells used as inocula were grown with ammonium, nitrite or nitrate, a strong expression of complete NirA was observed, especially from $3 \mathrm{~h}$ to $24 \mathrm{~h}$ of culture. In most cases the complete protein coexists with the truncated NirA, even though the expression levels of the latest one are always lower. Finally, when cells grown with ammonium, nitrite or nitrate were used to inoculate flasks with fresh $\mathrm{N}$-free media, the complete NirA is the protein mainly expressed in most cases, although cell growth is scarce. These results indicate that NirA protein is expressed in cells of T. elongatus BP-1, even in conditions of nitrogen depletion.

The effect of light during the expression of NirA was assessed in T. elongatus BP-1 cultures either continuously illuminated or subjected to darkness by covering flasks with aluminum foil and incubated under the same conditions. The same regulatory effect was observed in light and dark cultures, although the expression of the complete and truncated forms of NirA appeared enhanced in cultures grow under continuous illumination (data not shown). To confirm the differences observed in the images (Figure 4, lower panels), Western blot membranes were analyzed quantitatively and the obtained results appear in Supplementary Table 1.

\section{Discussion}

In this paper we have cloned nirA gene in E. coli cells in order to express and purify enough amount of recombinant $\mathrm{His}_{6} \mathrm{NirA}$ protein to be used as immunogen to obtain polyclonal antibodies. The analysis of $E$. coli ex- 
tracts with these antibodies revealed the presence of two forms of the expressed protein, the active complete (58 $\mathrm{kDa})$ and inactive truncated $(44 \mathrm{kDa})$ forms of $\mathrm{His}_{6} \mathrm{NirA}$. Moreover, the antibodies also recognized the presence of both proteins in active fractions (showing NirA activity) collected from the gradient elution (at $250 \mathrm{mM} \mathrm{im}-$ idazole) of the IMAC column used to purify the recombinant protein.

The calculated theoretical molecular mass of $\mathrm{His}_{6} \mathrm{NirA}(58,487 \mathrm{kDa})$ corresponds to the complete protein which appears as the upper band in samples analyzed by SDS-PAGE. Moreover, fractions containing both proteins show NirA activity, indicating that the siroheme and [4Fe-4S] groups are linked to the mature protein, and that the level of prosthetic groups is enough to provide some enzyme activity, even when the recombinant protein is expressed in E. coli cells. However, as occurred when other nitrite and sulphite reductases were expressed in E. coli cells [27], some of the newly synthesized apoprotein remains inactive due to the loss of siroheme in some enzyme molecules during the purification procedure, or because the amount of siroheme and/or [4Fe-4S] cluster available in $E$. coli cells is insufficient to assemble with all the de novo synthesized apoprotein providing the fully active holoprotein.

To discard that the observed presence of both forms of $\mathrm{His}_{6} \mathrm{NirA}$ was due to an artifact or proteolysis during isolation, the recombinant protein purification was repeated several times using different $E$. coli cultures and preventing proteolysis by working in cold $\left(\right.$ at $\left.4^{\circ} \mathrm{C}\right)$ and using a protease inhibitors cocktail. In all cases consistent results were obtained, although the use of the inhibitors cocktail both protein forms was always detected in active fractions of the recombinant enzyme collected from the IMAC column. These results suggested that the truncated protein was present in intact cells of $E$. coli and was not originated during the purification procedure.

Similar results were obtained in our laboratory when the native NirA was purified from wild-type cells of the thermophilic cyanobacterium P. laminosum. In this case, the presence of the complete enzyme of $54 \mathrm{kDa}$ together with a smaller form of $40 \mathrm{kDa}$ was reported, although the presence of the smaller form was then explained assuming partial proteolysis of the native NirA during purification [11].

SDS-PAGE analysis followed by Western blotting, using anti-His ${ }_{6}$ tag monoclonal antibody, showed that the truncated form of $\mathrm{His}_{6} \mathrm{NirA}$ contained the $\mathrm{His}_{6}$-tag, too. This result was expected taking into account that this form was strongly retained in the IMAC column and coeluted with the intact form at the end of the imidazole gradient. Furthermore, when these analyses were used to assess the induction time-course of $\mathrm{His}_{6} \mathrm{NirA}$ by IPTG in $E$. coli cells, both proteins were once more expressed and detected together, confirming that the $44 \mathrm{kDa}$ protein was already present in intact cells of $E$. coli. Similar results were reported when the recombinant spinach NirA was expressed in E. coli [27]. In this case, SDS-PAGE followed by Western blotting demonstrated that the recombinant NirA was already degraded during the early stages of induction by IPTG leading to a major band of degradation.

Combining former assays with peptide identification after mass spectrometry analysis of the bands sliced from SDS-PAGE gels corresponding to the $58 \mathrm{kDa}$ and $44 \mathrm{kDa}$ proteins confirms that the $44 \mathrm{kDa}$ band corresponds to a truncated $\mathrm{Hi}_{6} \mathrm{NirA}$ lacking a polypeptide of about $14,632 \mathrm{kDa}$ located at the carboxyl domain. Such a marked pattern of proteolysis, leading to the $44 \mathrm{kDa}$ protein as the major degradation product, strongly suggests that a region particularly exposed or accessible to proteases action will exist within the carboxyl domain sequence of NirA. This issue might be explained by sequence alignment of some sulphite and nitrite reductases from several prokaryotic and eukaryotic organisms (Figure 5). Some studies demonstrated that these four cysteine residues responsible for anchoring the [4Fe-4S] cluster and siroheme group were present along the carboxyl domain of these proteins [28]-[31]. Proteolysis of $\mathrm{His}_{6} \mathrm{NirA}$ might be based on the proper structure of NirA, as well as on the conformation acquired by the protein depending on whether it has linked or not the corresponding prosthetic groups. Furthermore, the amount of siroheme group synthesized by E. coli might be insufficient for all the apoprotein expressed by cells. In this case, those $\mathrm{His}_{6} \mathrm{NirA}$ molecules lacking the bound siroheme would present the carboxyl extreme region more exposed and accessible to the action of proteases, being more susceptible to be hydrolyzed.

The presence of the truncated form of $\mathrm{His}_{6} \mathrm{NirA}$ apparently depends on a nonspecific proteolysis occurring in a particular site located at the carboxyl terminal extreme. This hydrolysis is independent of the nitrogen source used to grow E. coli cells. Surprisingly, NirA also appeared in wild-type cells of T. elongatus BP-1 as an active protein of $58 \mathrm{kDa}$ and its inactive truncated form of $44 \mathrm{kDa}$, although their origin and physiological implications might be completely different in both situations. In wild-type cells, the presence of the truncated form appears to be regulated by a proteolytic process apparently dependent on the nitrogen source used to grow the cyanobacterium. This regulatory pattern was observed both in cultures continuously illuminated and subjected to darkness, although it was more remarkable in illuminated cultures (data not shown). 


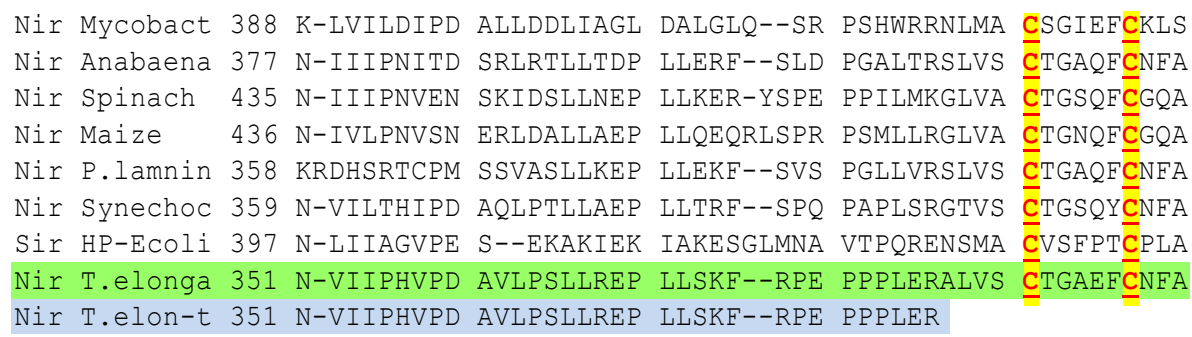

Figure 5. Alignment of partial sequences of nitrite reductase (denoted as Nir or NirA) and sulphite reductase (Sir) from several bacteria, cyanobacteria and higher plants: Nir from $M y$ cobacterium tuberculosis (GenBank ID:NP_336942.1), Nir from Anabaena sp. PCC 7120 (GenBank ID:BAB72565.1), Nir from spinach (PDB ID:2AKJ A), Nir from maize (GenBank ID:AAA60450), NirA from P. laminosum (GenBank ID:CAA79655.1), Nir from Synechococcus sp. PCC 7942 (GenBank ID:CAA47912.1), hemoprotein component of sulphite reductase (SirHP) from E. coli (PDB:1AOP_A), complete NirA from T. elongatus BP-1 (GenBank ID:BAC08901) and truncated NirA from T. elongatus BP-1 obtained after IMAC purification. The four Cys residues involved in the anchoring of the prosthetic groups appear shadowed in yellow, and types underlined and in red color. The sequences of the complete and truncated forms of NirA from T. elongatus BP-1 are shadowed with different colors. Alignment was performed using Vector $\mathrm{NTI}^{\circledR}$ software available at:

http://www.lifetechnologies.com/es/en/home/life-science/cloning/vector-nti-software.html.

The in vivo expression profile of NirA in cells of T. elongatus BP-1 demonstrates that the nirA operon is repressed by ammonium but it is transcribed in nitrate-or nitrite-containing medium, or even in a $\mathrm{N}$-free medium. The truncated $44 \mathrm{kDa}$ form of NirA is mainly present in cells grown with nitrate or nitrite and then transferred to ammonium-containing medium and in most cases of nitrite growing cells despite the nitrogen source used to grow inocula. The complete $58 \mathrm{kDa}$ protein was the predominant form in cells growing with nitrate and in most cases of cells transferred to a $\mathrm{N}$-free medium, despite the nitrogen source used to grow inocula. These results 
confirm those obtained by measuring its activity in vitro and show that NirA is more ammonium-repressible than nitrate- or nitrite-inducible.

The effect of light on the in vivo regulation of several enzymes involved in nitrate assimilation in cultures of Synechococcus leopoliensis has been studied by Tischner and Schmidt [32]. These authors concluded that light increased the specific activity of some of them (including NirA), whereas other decreased or remained nearly unchanged. Recently, Ludwig and Bryant [33] also reported the necessary acclimation of the global transcriptome of the cyanobacterium Synechococcus sp. strain PCC 7002 to different nitrogen sources, taking into account that nitrate/nitrite assimilation is energetically expensive, and that the eight- or six-electrons donated by photosynthetically-reduced ferredoxin can consume $30 \%$ of the total reducing equivalents obtained by the photosynthetic light reactions used to provide cells with reduced ferredoxin. In this work we have not found any remarkable effect of light on the expression of nirA gene whose product utilizes six-electrons to reduce nitrite to ammonium. The only observed result is that in darkness the changes in expression appear lowered-down.

This study represents, to our knowledge, the first case suggesting that proteolysis of NirA could represent a post-translational regulatory mechanism of nitrate assimilation on a short-term basis and add a possible new element of regulation in this very complex system not yet elucidated.

\section{Acknowledgements}

This work was supported by the University of the Basque Country (UPV/EHU) (Grants GIU07/55 and GIU11/ 25). A strain of T. elongatus BP-1 cells was kindly provided by Prof. M. Rögner (University of Bochum, Germany). We thank the contribution of Miss Patricia Barrera during some part of this work. MB was the recipient of a scholarship from the UPV/EHU.

\section{References}

[1] Flores, E. and Herrero, A. (2005) Nitrogen Assimilation and Nitrogen Control in Cyanobacteria. Biochemical Society Transactions, 33, 164-167. http://dx.doi.org/10.1042/BST0330164

[2] Flores, E., Frías, J.E., Rubio, L.M. and Herrero, A. (2005) Photosynthetic Nitrate Assimilation in Cyanobacteria. Photosynthesis Research, 83, 117-133. http://dx.doi.org/10.1007/s11120-004-5830-9

[3] Aichi, M., Yoshihara, S., Yamashita, M., Maeda, S., Nagai, K. and Omata, T. (2006) Characterization of the NitrateNitrite Transporter of the Major Facilitator Superfamily (the nrtP Gene Product) from the Cyanobacterium Nostoc punctiforme Strain ATCC 29133. Bioscience Biotechnology and Biochemistry, 70, 2682-2689. http://dx.doi.org/10.1271/bbb.60286

[4] Ohashi, Y., Shi, W., Takatani, N., Aichi, M., Maeda, S.-i., Watanabe, S., et al. (2011) Regulation of Nitrate Assimilation in Cyanobacteria. Journal of Experimental Botany, 62, 1411-1424. http://dx.doi.org/10.1093/jxb/erq427

[5] Frías, J.E., Flores, E. and Herrero, A. (1997) Nitrate Assimilation Gene Cluster from the Heterocyst-Forming Cyanobacterium Anabaena sp. Strain PCC 7120. Journal of Bacteriology, 179, 477-486.

[6] Vega, J.M. and Kamin, H. (1977) Spinach Nitrite Reductase. Purification and Properties of a Siroheme-Containing Iron-Sulphur Enzyme. Journal of Biological Chemistry, 252, 896-909.

[7] Stroupe, M.E. and Getzoff, E.D. (2009) The Role of Siroheme in Sulfite and Nitrite Reductases. In: Warren, M.J. and Smith, A.G., Eds., Tetrapyrroles: Birth, Life and Death, Springer Science+Business Media, LLC, New York, 375-389.

[8] Méndez, J.M. and Vega, J.M. (1981) Purification and Molecular Properties of Nitrite Reductase from Anabaena sp. Physiologia Plantarum, 52, 7-14. http://dx.doi.org/10.1111/j.1399-3054.1981.tb06026.x

[9] Yabuki, Y., Mori, E. and Tamura, G. (1985) Nitrite Reductase in the Cyanobacterium Spirulina platensis. Agricultural and Biological Chemistry, 49, 3061-3062. http://dx.doi.org/10.1271/bbb1961.49.3061

[10] Guerrero, M.G. and Lara, C. (1987) Assimilation of Inorganic Nitrogen. In: Fay, P. and van Baalen, C., Eds., The Cyanobacteria, Elsevier Science Publishers B.V., Amsterdam, 163-186.

[11] Arizmendi, J.M. and Serra, J.L. (1990) Purification and Some Properties of the Nitrite Reductase from the Cyanobacterium Phormidium laminosum. Biochimica et Biophysica Acta (BBA), Protein Structure and Molecular Enzymology, 1040, 237-244. http://dx.doi.org/10.1016/0167-4838(90)90082-Q

[12] Suzuki, I., Kikuchi, H., Nakanishi, S., Fujita, Y., Sugiyama, T. and Omata, T. (1995) A Novel Nitrite Reductase Gene from the Cyanobacterium Plectonema boryanum. Journal of Bacteriology, 177, 6137-6143.

[13] Flores, E., Guerrero, M.G. and Losada, M. (1980) Short-Term Ammonium Inhibition of Nitrate Utilization by Anacystis nidulans and Other Cyanobacteria. Archives of Microbiology, 128, 137-144. http://dx.doi.org/10.1007/BF00406150 
[14] Arizmendi, J.M., Fresnedo, O., Martínez-Bilbao, M., Alaña, A. and Serra, J.L. (1987) Inorganic Nitrogen Assimilation in the Non- $\mathrm{N}_{2}$-Fixing Cyanobacterium Phormidium laminosum. II. Effect of the Nitrogen Source on the Nitrite Reductase Levels. Physiologia Plantarum, 70, 703-707. http://dx.doi.org/10.1111/j.1399-3054.1987.tb04327.x

[15] Kobayashi, M., Takatani, N., Tanigawa, M. and Omata, T. (2005) Posttranslational Regulation of Nitrate Assimilation in the Cyanobacterium Synechocystis sp. Strain PCC 6803. Journal of Bacteriology, 187, 498-506. http://dx.doi.org/10.1128/JB.187.2.498-506.2005

[16] Herrero, A. and Guerrero, M.G. (1986) Regulation of Nitrite Reductase in the Cyanobacterium Anacystis nidulans. Journal of General Microbiology, 132, 2463-2468.

[17] Tapia, M.I., Llama, M.J. and Serra, J.L. (1996) Regulation of Nitrate Assimilation in the Cyanobacterium Phormidium laminosum. Planta, 198, 24-30. http://dx.doi.org/10.1007/BF00197582

[18] Puerta-Fernández, E. and Vioque, A. (2011) Hfq Is Required for Optimal Nitrate Assimilation in the Cyanobacterium Anabaena sp. Strain PCC 7120. Journal of Bacteriology, 193, 3546-3555. http://dx.doi.org/10.1128/JB.00254-11

[19] Frías, J.E. and Flores, E. (2010) Negative Regulation of Expression of the Nitrate Assimilation nirA Operon in the Heterocyst-Forming Cyanobacterium Anabaena sp. Strain PCC 7120. Journal of Bacteriology, 192, 2769-2778. http://dx.doi.org/10.1128/JB.01668-09

[20] Nakamura, Y., Kaneko, T., Sato, S., Ikeuchi, M., Katoh, H., Sasamoto, S., et al. (2002) Complete Genome Structure of the Thermophilic Cyanobacterium Thermosynechococcus elongatus BP-1. DNA Research, 9, 123-130. http://dx.doi.org/10.1093/dnares/9.4.123

[21] Buxens, M., Serra, J.L. and Llama, M.J. (2013) Substitution of the Nitrite Reductase of Thermosynechococcus elongatus BP-1 by the Homologous Gene of Phormidium laminosum. Advances in Microbiology, 3, 69-79. http://dx.doi.org/10.4236/aim.2013.36A009

[22] Stanier, R.Y., Kunisawa, R., Mandel, M. and Cohen-Bazire, G. (1971) Purification and Properties of Unicellular BlueGreen Algae (Order Chroococcales). Bacteriological Reviews, 35, 171-205.

[23] Bradford, M. (1976) A Rapid and Sensitive Method for the Quantitation of Microgram Quantities of Protein Utilizing the Principle of Protein-Dye Binding. Analytical Biochemistry, 72, 248-254. http://dx.doi.org/10.1016/0003-2697(76)90527-3

[24] Mathiesen, R., Bunkenborg, J., Stensballe, A., Jensen, O.N., Welinder, K.G., Bauw, G. (2004) Database-Independent, Database-Dependent, and Extended Interpretation of Peptide Mass Spectra in VEMS V2.0. Proteomics, 4, 2583-2593. http://dx.doi.org/10.1002/pmic.200300792

[25] Hess, A.V.I. (2007) Digitally-Enhanced Thin-Layer Chromatography: An Inexpensive, New Technique for Qualitative and Quantitative Analysis. Journal of Chemical Education, 84, 842-847. http://dx.doi.org/10.1021/ed084p842

[26] Serra, J.L., Llama, M.J. and Cadenas, E. (1978) Nitrate Utilization by the Diatom Skeletonema costatum. II. Regulation of Nitrate Uptake. Plant Physiology, 62, 991-994. http://dx.doi.org/10.1104/pp.62.6.991

[27] Bellissimo, D.B. and Privalle, L.S. (1995) Expression of Spinach Nitrite Reductase in Escherichia coli: Site-Directed Mutagenesis of Predicted Active Site Amino Acids. Archives of Biochemistry and Biophysics, 323, 155-163. http://dx.doi.org/10.1006/abbi.1995.0021

[28] Ostrowski, J., Wu, J.Y., Rueger, D.C., Miller, B.E., Siegel, L.M. and Kredrich, M. (1989) Characterization of the cysJIH Regions of Salmonella typhimurium and Escherichia coli. Journal of Biological Chemistry, 264, 15726-15737.

[29] Luque, I., Flores, E. and Herrero, A. (1993) Nitrite Reductase Gene from Synechococcus sp. PCC 7942: Homology between Cyanobacterial and Higher-Plant Nitrite Reductases. Plant Molecular Biology, 21, 1201-1205. http://dx.doi.org/10.1007/BF00023618

[30] Schnell, R., Sandalova, T., Hellman, U. and Schneider, G. (2005) Siroheme and [Fe4-S4]-Dependent nirA from Mycobacterium tuberculosis Is a Sulphite Reductase with a Covalent Cys-Tyr Bond in the Active Site. Journal of Biological Chemistry, 280, 27319-27328. http://dx.doi.org/10.1074/jbc.M502560200

[31] Swamy, U., Wang, M., Tripathy, J.N., Kim, S.K., Hirasawa, M., Knaff, D.B., et al. (2005) Structure of Spinach Nitrite Reductase: Implications for Multi-Electron Reactions by the Iron-Sulphur: Siroheme Cofactor. Biochemistry, 44, 16054-16063. http://dx.doi.org/10.1021/bi050981y

[32] Tischner, R. and Schmidt, A. (1984) Light Mediated Regulation of Nitrate Assimilation in Synechococcus leopoliensis. Archives in Microbiology, 137, 151-154. http://dx.doi.org/10.1007/BF00414457

[33] Ludwig, M. and Bryant, D.A. (2012) Acclimation of the Global Transcriptome of the Cyanobacterium Synechococcus sp. Strain PCC 7002 to Nutrient Limitations and Different Nitrogen Sources. Frontiers in Microbiology, 3, 145. http://dx.doi.org/10.3389/fmicb.2012.00145 


\section{Supplementary}

Table 1. Levels of complete $(58 \mathrm{kDa})$ and truncated $(44 \mathrm{kDa})$ forms of NirA assessed by SDS-PAGE followed by Western blotting of samples of cultures shown in Figure 4. Cells grown in ammonium (a), nitrite (b) or nitrate (c) were used to inoculate culture media containing the indicated nitrogen source or $\mathrm{N}$-free medium.

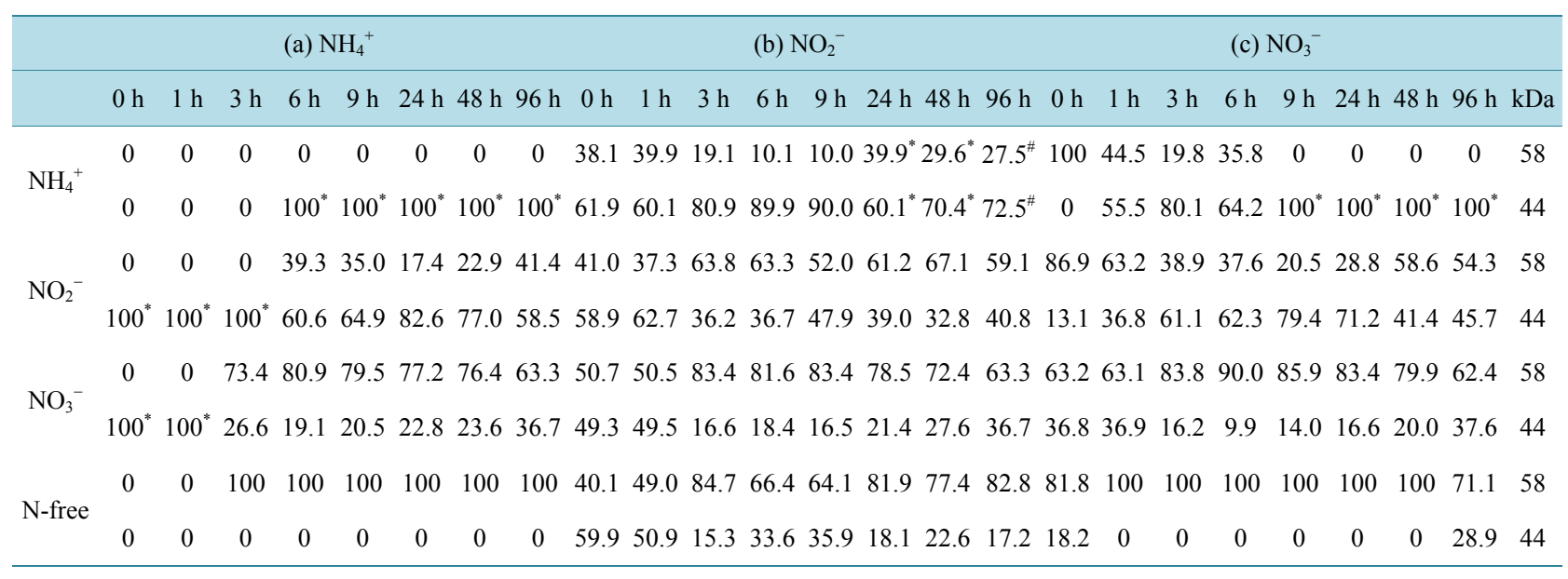

Figures represent percentages calculated for both forms after digital analysis of Western blot membranes and numerical integration. In the cases where one band of protein of molecular mass comprised between the complete and truncated forms appeared, its amount was added to that of the $58 \mathrm{kDa}$ form. Conversely, where the band showed a mass lower than that of the truncated form, its amount was added to that of the $44 \mathrm{kDa}$ form. ${ }^{*}$ Negligible amounts of protein were detected. "In replicated blotting membranes only the truncated form was detected. 
Scientific Research Publishing (SCIRP) is one of the largest Open Access journal publishers. It is currently publishing more than 200 open access, online, peer-reviewed journals covering a wide range of academic disciplines. SCIRP serves the worldwide academic communities and contributes to the progress and application of science with its publication.

Other selected journals from SCIRP are listed as below. Submit your manuscript to us via either submit@scirp.org or Online Submission Portal.
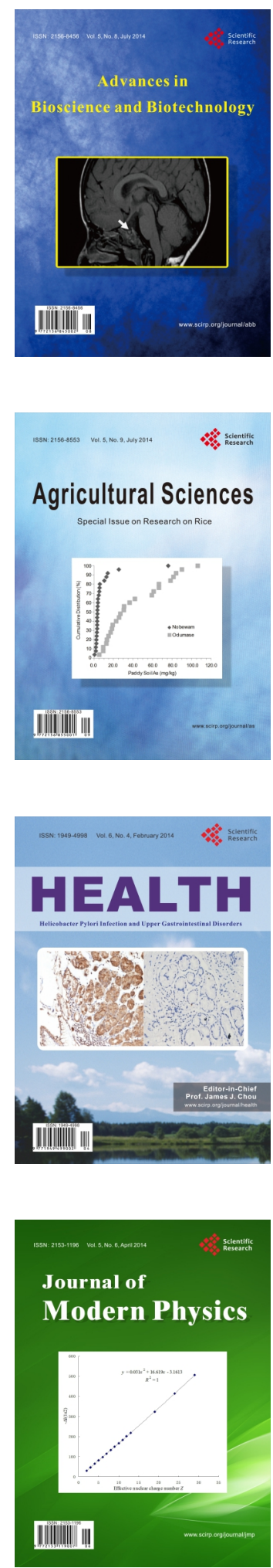
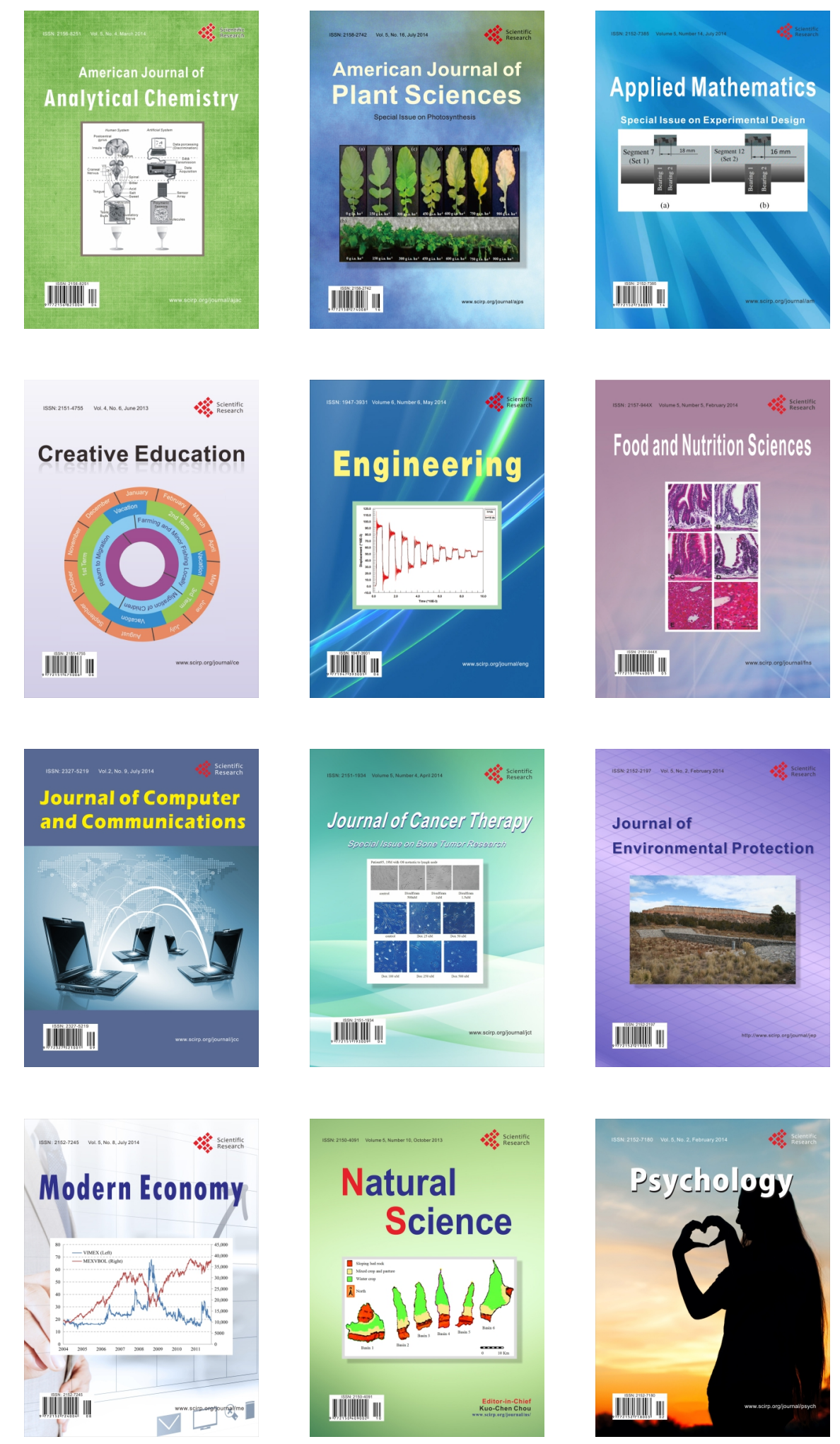